\title{
Transfer of Moraxella kingae Henriksen and Bøvre to the Genus Kingella gen. nov. in the Family Neisseriaceae
}

\author{
S. D. HENRIKSEN AND K. BØVRE
}

Kaptein W. Wilhelmsen og Frues Bakteriologiske Institutt, University of Oslo, Rikshospitalet, Oslo 1 , Norway, and Institute of Medical Biology, University of Troms $\phi$ N-9000 Troms $\phi$, Norway

Many specialists have considered Moraxella kingae Henriksen and Bøvre not to belong to the genus Moraxella because it differs from the other Moraxella species in several characters and apparently does not have genetic affinities to the other species. For these reasons, the transfer of $M$. kingae to the genus Kingella gen. nov. in the family Neisseriaceae is proposed.

The species Moraxella kingae Henriksen and Bøvre, originally described under the name $M$. kingii (14), later corrected to $M$. kingae (8), was classified as a Moraxella species because it showed some striking similarities to members of Moraxella. Because of some likewise striking differences from Moraxella species, in particular production of acid from certain sugars and lack of catalase activity, this classification has not been well received and has not met with the approval of the Subcommittee on the Taxonomy of Moraxella and Allied Bacteria (19). Sufficient evidence is now available to justify the transfer of this species to a new, separate genus within the same family, Neisseriaceae. A summary of the evidence is given below.

Characters of $M$. kingae shared with moraxellae: (i) micromorphology. Plump, gramnegative rods and coccobacilli with obtuse or nearly square ends, occurring in pairs and short chains. Films from 18- to 20-h-old agar cultures show very distinct staining with some tendency to retain the Gram stain. No swimming motility. May or may not show twitching motility (12) and fimbriation with polar fimbriae $(10,11)$.

(ii) Colonies. Two different varieties may occur: (i) the spreading-corroding type of colony $(13,16)$, which is associated with twitching motility, fimbriation, and competence in transformation $(6,10,12)$; and (ii) the smooth, stationary, normal type of colony, which does not show spreading, corrosion, twitching, fimbriation, or competence. Similar colony variations have been found in $M$. nonliquefaciens and $M$. bovis $(5,6,12)$ as well as in Neisseria gonorrhoeae and $N$. meningitidis (11) and in N. elongata (to be published).

(iii) Physiology. Apparently physiologically fastidious, producing only moderate growth on many of the customary media, e.g., nutrient agar or peptone water media. Aerobic. Meso- philic. Comparatively short-lived on blood agar at $35^{\circ} \mathrm{C}$ and at room temperature.

(iv) Biochemical reactions. Positive oxidase reaction, negative indole and $\mathrm{H}_{2} \mathrm{~S}$ reactions.

(v) Antibiotic susceptibility. Susceptible to penicillin, streptomycin, chloramphenicol, tetracyclines, erythromycin, and sulfonamides.

(vi) Habitat. Parasitic on mucous membranes. So far, isolated only from human sources.

Differences between $M$. kingae and moraxellae: (i) biochemical reactions. Acid production from glucose, maltose, and galactose (a trace). Negative catalase reaction, tested by dropping $10 \% \mathrm{H}_{2} \mathrm{O}_{2}$ on to nutrient agar slant cultures. Hemolytic action on blood agar (in agreement with $M$. bovis and $N$. ovis, but in disagreement with other Moraxella species). (Opinions are divided as to whether the "false neisseriae" should be classified in Branhamella (9) or in Moraxella (15). We favor the latter alternative, but the designation Neisseria is used here while this taxonomic problem is reexamined experimentally.)

(ii) Fatty acid composition. All other Moraxella species cluster together with regard to fatty acid composition, whereas $M$. kingae has a clearly different fatty acid pattern as demonstrated in a phenogram, obtained by the unweighted pair group analysis of Sokal and Mitchner (17), of the fatty acid contents of $M$. kingae compared with other moraxellae and neisseriae.

Nondistinctive characters. In a number of other characters, there is variation among $M o r$ axella species and no systematic difference between $M$. kingae and the other species.

Genetic avidence. Available genetic data showing affinities of the members of the family Neisseriaceae obtained by transformation experiments $(2,7)$, nucleic acid hybridization (3), and determination of the deoxyribonucleic acid 
(DNA) base composition (4) may be roughly summarized as follows. (i) Commonly recognized Moraxella species (except $M$. kingae) appear to form a continuum of affinities, from very low (e.g., between $M$. phenylpyrouvica and $M$. nonliquefaciens) to intermediate (e.g., between $M$. bovis and $N$. ovis) to high (as between the "classical moraxellae" $M$. lacunata, $M$. nonliquefaciens, and $M$. bovis) $(2,3,7$; unpublished data). (ii) The genetic affinities of Acinetobacter to this large group are generally very low, but sometimes they are distinct (as towards $N$. catarrhalis) and partly overlap with the lowest mutual affinities found in the oxidase-positive group mentioned $(2,3)$. (iii) The species of the "true" genus Neisseria (after exclusion of $N$. catarrhalis, N. ovis, and N. caviae) which have been tested appear mutually closely related and clearly separated from the above-mentioned organisms, with no distinct sign of affinity to them $(2,3)$. (iv) $M$. kingae, having been tested extensively in genetic transformation, has revealed no affinity to any strain of Moraxella, "false neisseriae," or Acinetobacter, and generally not to the genus Neisseria. However, an uncertain, marginal affinity was recently observed towards $N$. elongata (to be published).

\section{DISCUSSION}

The main differences in conventional characters, in fact the only significant ones, between $M$. kingae and the other Moraxella species are the acid production from sugars by $M$. kingae, a character it shares with many Neisseria species, and lack of catalase. Another phenotypic complex trait which clearly separates $M$. kingae from the other moraxellae and the "false neisseriae" is its pattern of fatty acid composition, as revealed by gas chromatography (17).

The genetic evidence also strongly indicates that $M$. kingae is not closely related to Moraxella or to other genera of the family Neisseriaceae. Even if significant, the very weak transformation interactions observed with $N$. elongata do not appear sufficient to consider $M$. kingae as having genus affinity to Neisseria. They may, however, indicate a relationship corresponding to different genera of the same family.

The rather unique fatty acid composition of $M$. kingae still falls within the general pattern of members of Neisseriaceae, with some similarity to that of members of the genus Neisseria (17).

The possibility of sufficient affinity of M. kingae to the neisseriae for the former to be included in Neisseria finds no support in the fol- lowing observations. The guanine plus cytosine $(\mathrm{G}+\mathrm{C})$ content of the DNA of $M$. kingae when determined by buoyant density, $44.5 \mathrm{~mol} \%(4)$, is significantly lower than that for the neisseriae. By gas chromatographic analysis of cellular monosaccharide content, $M$. kingae differs from all examined "true neisseriae" in its lack of heptose (E. Jantzen, K. Bryn, and K. Bøvre, Acta Pathol. Microbiol. Scand. Sect. B, in press). Finally, $M$. kingae reveals activities corresponding to the enzymes thymidine phosphorylase, nucleoside deoxyribosyltransferase, and thymidine kinase, which are absent from Neisseria species as well as from most Moraxella speces (18).

Consequently, $M$. kingae appears isolated in the family Neisseriaceae. So also does the genus Neisseria, however, and there is no more reason to remove $M$. kingae from the family than to place Neisseria and Moraxella in different families. There are, rather, considerably indications (morphology like Moraxella, fermentation reactions like some Neisseria species, same habitat, $\mathrm{G}+\mathrm{C}$ content within the range of Neisseriaceae, oxidase reaction, antibiotic susceptibility) that $M$. kingae does indeed fit into the family Neisseriaceae, and it would be difficult to find a more suitable family for this species. However, the lack of clearly demonstrable genetic homologies with the other members of the family and some of the phenotypic traits of $M$. kingae make it reasonable to create a new genus in the family Neisseriaceae for this species.

Only a few people have worked with $M$. kingae, and we feel that it is appropriate to derive the generic name for this and any related organisms from the name of Elizabeth $\mathrm{O}$. King, the first to call attention to this organism. Consequently, we propose the name Kingella for the new genus (King.el'la. M.L. dim. ending ella; M.L. fem.n. Kingella; named after Elizabeth O. King, an American bacteriologist).

The question arises whether there are any other candidates for the new genus. The possibility that the "new" moraxellas described by van Bijsterveld (1) and by Sutton et al. (20), which must belong to the same species on the basis of transformation data (unpublished), might be related to $M$. kingae has been suggested. However, there are some marked differences between these organisms and $M$. kingae in morphology, in attack on sugars, and in indole production as well as in DNA base composition. Previous $(1,4)$ and repeated experiments by buoyant density determinations by the method and calculation described (4) have given 44.5 to $45.0 \mathrm{~mol} \% \mathrm{G}+\mathrm{C}$ for $M$. kingae 
and 48 to 49 mol\% for van Bijsterveld's strain, partly in simultaneous analytical centrifuge runs (unpublished data). The question of the relationship of these organisms must be left open for the time being. As far as we are aware, there are no other obvious candidates for this new genus.

\section{Description of Kingella gen. nov.}

The proposed genus Kingella is monospecific, and the following description therefore is a combined generic and specific description.

Micromorphology. The cells are coccoid to medium-sized rods, very much like those of Moraxella but slightly smaller, have square ends, and occur in pairs and short chains. Gram negative, with some tendency to resist decolorization. Not encapsulated. Not motile. Endospores are not produced.

Colonies. Two types of colonies occur. On blood agar, colonies of freshly isolated strains often first appear as small depressions, 0.1 to $0.5 \mathrm{~mm}$ in diameter, with a small central papilla. After incubation for 2, 3, or more days, the colonies show considerable peripheral spread, increasing to diameters of 4 to $5 \mathrm{~mm}$. Thin granular zones of growth often surround the colonies. When the growth is scraped off, corrosion marks in the agar surface become apparent. This type of spreading-corroding growth is associated with polar fimbriation of the cells, twitching motility, competence in genetic transformation, and a tendency to pellicle formation when growing in fluid media. The second type of colony, which often arises in subcultures of the first type, is small, delicate, translucent or slightly opaque, 0.1 to $0.6 \mathrm{~mm}$ in diameter after $20 \mathrm{~h}$ on blood agar, low hemispherical, and smooth. After further incubation, the colonies increase somewhat in size, but do not spread or corrode, and are not associated with the same characters as the first type of colony. Both kinds of colony are surrounded by distinct zones of beta-hemolysis. The consistency is soft or coherent. No pigment.

Relation to oxygen. Aerobic.

Temperature. Slight growth at room temperature (about $20^{\circ} \mathrm{C}$ ). Optimal growth at 33 to $37^{\circ} \mathrm{C}$. Usually killed by exposure to $45^{\circ} \mathrm{C}$ for 10 to $30 \mathrm{~min}$.

Growth requirements. Relatively fastidious. Little or no growth occurs in peptone media. There is no growth on Hugh and Leifson $\mathrm{O} /$ $\mathrm{F}$ medium and practically no improvement of growth by the addition of $10 \%$ ( $\mathrm{vol} / \mathrm{vol}$ ) horse serum to liquid peptone media. Growth on high quality nutrient agar is almost as good as that on blood agar. There is no apparent need for $\mathrm{X}$ or $\mathrm{V}$ factors or for $\mathrm{CO}_{2}$ in the atmosphere.

Viability. Blood agar cultures become sterile within 6 to 12 days at room temperature.

Biochemical reactions. Catalase reaction, negative. Oxidase reaction, strongly positive with tetramethyl-, less strongly positive with dimethyl-p-phenylenediamine. Nitrate not reduced or slightly reduced. Acid rapidly produced on ascites fluid agar slopes from glucose and maltose. Trace of acid from galactose. No acid from fructose, lactose, saccharose, arabinose, xylose, rhamnose, mannitol, dulcitol, sorbitol, or glycerol. Gelatin and serum are not liquefied. Indole and hydrogen sulfide are not produced. Urease negative. No oxidative deamination of phenylalanine or tryptophane.

Antibiotic susceptibility. Highly susceptible to penicillin, streptomycin, chloramphenicol, oxytetracycline, and erythromycin.

Habitat. Parasitic on human mucous membranes. Strains have been isolated from throat, nose, blood, bone lesions and joints.

Pathogenicity. Uncertain, probably low.

DNA base composition. 44.5 to $45 \mathrm{~mol} \% \mathrm{G}+$ $\mathrm{C}$ ( $\mathrm{CsCl}$ buoyant density method).

Genetic compatibilities. Strains are mutually compatible with ratios of interstrain to intrastrain transformant numbers close to 1 . No compatibility with moraxellae or neisseriae except for an uncertain, marginal affinity to $N$. elongata.

Type strain. (For original designation, see reference 16.) $4177 / 66(=$ ATCC $23330=$ NCTC 10529).

\section{REPRINT REQUESTS}

Address reprint requests to: Dr. S. D. Henriksen, Kaptein W. Wilhelmsen og Frues Bakteriologiske Institutt, University of Oslo, Rikshospitalet, Oslo 1, Norway.

\section{LITERATURE CITED}

1. Bijsterveld, O. P. van. 1970. New Moraxella strain isolated from angular conjunctivitis. Appl. Microbiol. 20:405-408.

2. Bøvre, K. 1967. Transformation and DNA base composition in taxonomy, with special reference to recent studies in Moraxella and Neisseria. Acta Pathol. Microbiol. Scand. 69:123-144.

3. Bøvre, K. 1970. Pulse RNA-DNA hybridization between rod-shaped and coccal species of the Moraxella-Neisseria group. Acta Pathol. Microbiol. Scand. Sect. B 78:565-574.

4. Bovre, K., M. Fiandt, and W. Szybalski. 1969. DNA base composition of Neisseria, Moraxella and Acinetobacter determined by measurement of buoyant density in $\mathrm{CsCl}$ gradients. Can. J. Microbiol. 15:335-338.

5. Bøvre, K., and L. O. Frøholm. 1972. Variation of colony morphology reflecting fimbriation of Moraxella bovis and two reference strains of $M$. nonliquefaciens. Acta Pathol. Microbiol. Scand. Sect. B 80:639-640.

6. Bøvre, K., and L. O. Frøholm. 1972. Competence in 
genetic transformation related to colony type and fimbriation in three species of Moraxella. Acta $\mathrm{Pa}$ thol. Microbiol. Scand. Sect. B 80:649-659.

7. Bovre, K., J. E. Fuglesang, N. Hagen, E. Jantzen, and L. O. Frøholm. 1976. Moraxella atlantae sp. nov. and its distinction from Moraxella phenylpyrouvica. Int. J. Syst. Bacteriol. 26:511-521.

8. Bovre, K., S. D. Henriksen, and V. Jonsson. 1974 Correction of the specific epithet kingii in the combinations Moraxella kingii Henriksen and Bøvre 1968 and Pseudomonas kingii Jonsson 1970 to Kingae. Int. J. Syst. Bacteriol. 24:307.

9. Catlin, B. W. 1970. Transfer of the organism named Neisseria catarrhalis to Branhamella gen. nov. Int. J. Syst. Bacteriol, 20:155-159.

10. Frøholm, L. O., and K. Bøvre. 1972. Fimbriation associated with the spreading-corroding colony type of Moraxella kingii. Acta Pathol. Microbiol. Scand. Sect. B 80:641-648.

11. Henrichsen, J. 1972. Bacterial surface translocation: a survey and a classification. Bacteriol. Rev. 36:478503 .

12. Henrichsen, J., L. O. Froholm, and K. Bøvre. 1972 Studies on bacterial surface translocation. 2. Correlation of twitching motility and fimbriation in colony variants of Moraxella nonliquefaciens, $M$. bovis and $M$. kingii. Acta Pathol. Microbiol. Scand. Sect. B 80:445-452

13. Henriksen, S. D. 1969. Corroding bacteria from the respiratory tract. I. Moraxella kingii. Acta Pathol. Microbiol. Scand. 75:85-90.

14. Henriksen, S. D., and K. Bovre. 1968. Moraxella kingii spec. nov., a haemolytic, saccharolytic species of the genus Moraxella. J. Gen. Microbiol. 51:377-385.

15. Henriksen, S. D., and K. Bøvre. 1968. The taxonomy of the genera Moraxella and Neisseria. J. Gen. Microbiol. 51:387-392.

16. Henriksen, S. D., and K. Bøvre. 1969. Corroding and spreading colonies in Moraxella nonliquefaciens. Acta Pathol. Microbiol. Scand. 76:85-90.

17. Jantzen, E., K. Bryn, T. Bergan, and K. Bøvre. 1974. Gas chromatography of bacterial whole cell methanolysates. V. Fatty acid composition of neisseriae and moraxellae. Acta Pathol. Microbiol. Scand. Sect. B 82:767-779.

18. Jyssum, S., and K. Bøvre. 1974. Search for thymidine phosphorylase and thymine kinase in Moraxella, Acinetobacter, and allied bacteria. Acta Pathol. Microbiol. Scand. Sect. B 82:57-66.

19. Lessel, E. F. 1970. International Committee on Nomenclature of Bacteria, Subcommittee on the Taxonomy of Moraxella and Allied Bacteria. Minutes of Meeting, 11 August 1970. Int. J. Syst. Bacteriol. 21:213214.

20. Sutton, R. G. M., M. G. O'Keefe, M. A. Bundock, J. Jeboult, and M. Tester. 1972. Isolation of a new Moraxella from a corneal abscess. J. Med. Microbiol. 5:148-150. 